\title{
Medical Students Knowledge About Clinical Importance and Effective Teaching Methods of Anatomy
}

\author{
Enam Alhagh Charkhat Gorgich, ${ }^{1,2}$ Maryam Sarbishegi, ${ }^{2,3,}{ }^{*}$ Sanam Barfroshan, ${ }^{1,2}$ and Ayub Abedi ${ }^{1}$ \\ ${ }^{1}$ Student Research Committee, Zahedan University of Medical Sciences, Zahedan, Iran \\ ${ }^{2}$ Department of Anatomy, School of Medicine, Zahedan University of Medical Sciences, Zahedan, Iran \\ ${ }^{3}$ Cellular and Molecular Research Center, Zahedan University of Medical Sciences, Zahedan, Iran \\ "Corresponding author: Maryam Sarbishegi, Department of Anatomy, School of Medicine, Zahedan University of Medical Sciences, Zahedan, Iran. Tel: +98- 9195535681, E-mail: \\ sarbishegim@gmail.com
}

Received 2017 May 30; Revised 2017 June 24; Accepted 2017 September 05

\begin{abstract}
Background: Anatomy is taught to medical students during first and second years of study and there is a big interval between learning the theory and its usage in the clinic.

Objectives: The aim of this study was to evaluate medical students knowledge about clinical importance and effective teaching methods of anatomy.

Methods: This cross-sectional study was carried out on 225 preclinical and clinical medical students from the city of Zahedan, Iran, during October 2015 to April 2016. Participants were selected using the convenience sampling method. Data were collected using a three-part questionnaire after proving its validity and reliability. Data were reported as descriptive and analytical statistics $t$ test, ANOVA, Pearson correlation) by the SPSS software version 16. The significant level was set as $\mathrm{P}<0.05$.

Results: The results showed that preclinical students' mean knowledge score was $23.05 \pm 4.14$ and that of clinical students was 26.83 \pm 3.90. There was a significant difference between students' course $(P=0.001)$ and ward $(P=0.001)$ and their level of knowledge. The most effective methods of learning anatomy from the perspective of preclinical and clinical students were giving lectures by the teacher and clinical students mentioned teaching theoretical topics simultaneously with clinical tips.

Conclusions: Anatomy plays an important role in improving clinical skills of medical students. Changes in teaching methods and using novel methods may be effective for teaching and learning anatomy and improving the students' attitude regarding the clinical importance of anatomy.
\end{abstract}

Keywords: Knowledge, Medical Students, Anatomy, Teaching, Education

\section{Background}

Human anatomy is a field of science that studies the human body structures at three levels, macroanatomy, microanatomy, and developmental anatomy (1). Anatomy is an important lesson for medical students worldwide (2) and they must learn anatomy including gross anatomy, histology, and embryology; these are the major part of the basic sciences of medicine $(1,3)$. Many of the clinical specialists consider having enough knowledge of anatomy a prerequisite for performing safe and competent interventions in medicine $(4,5)$. Learning anatomy practically and with clinical approach is necessary for medical students to decrease the medical errors. Knowing the importance and clinical uses of anatomy, on the other hand, could help students improve their skills (6).

Anatomy is a necessity for general practitioners, surgeons and for all those, who are involved in invasive diagnostic and therapeutic procedures. Knowing the body structures and the position of vital organs is necessary in emergency situations because many of the emergency and resuscitation procedures, including cricothyroidotomy, chest tube and tracheal tube placement, and many of the physical examinations and diagnostic and therapeutic procedures are based on anatomy knowledge (7).

The first words medical students learn are about anatomy, nevertheless for most of them the first thing that comes to their minds with the word "anatomy" is a cadaver and dead bones and this is why they often do not have a positive attitude towards this subject (8). In one study it was shown that medical students had a negative attitude towards basic sciences, including anatomy and they believed that there was no association between theoretical and practical aspects of these sciences and they could not use the theoretical sciences in clinical situations (9). Another study on interns showed that they did not have a positive attitude towards use of basic sciences in wards and on patients' bedsides $(10,11)$. Some studies have stated that the negative attitude towards basic sciences, especially anatomy, is due to the lack of consistency between theoretical and clinical aspects $(12,13)$. 
In Iran, medical students, after finishing the basic sciences course and passing the national basic medical sciences exam, which is mainly about anatomy, enter hospitals and learn physical examination and signs and symptoms of diseases. Therefore, learning basic sciences, including anatomy correctly and practically could help them with their jobs and provide necessary clinical skills (14).

Teaching anatomy, unlike other basic science lessons, such as biochemistry and physiology, needs a particular method of teaching and appropriate tools. These tools include a cadaver, molding (moulage), human body atlases, and educational movies and slides (10). There are different methods for teaching anatomy; in the traditional method, teaching is based on giving lectures. In this method the students are required to memorize a lot of information without knowing their importance and usage $(15,16)$. Therefore, most of this information is forgotten rapidly and the students do not have any interest in learning them again. Considering the fact that medical students need the knowledge of anatomy in their clinical courses, the methods of teaching and the tools have completely changed (17).

One of the major concerns for medical students is connecting theoretical subjects with practical ones and their usage in the clinic. For this purpose and in order to make the medical students interested in anatomy, various new methods have been proposed, which could improve their practical skills $(17,18)$. In these methods the students, while studying the theoretical subjects, are introduced to body structures and functions on a live and healthy person and then learn their practical usage (19). In the problem-based learning curricula (PBL) or horizontal integration method, instead of teaching anatomy, separately, there is a focus on one subject and subjects are taught systematically. In the vertical integration, on the other hand, teaching basic sciences and clinical lessons is done together and the students don't learn these lessons separately (19-21).

The first step in planning educational programs is evaluating the level of knowledge of study groups and their needs assessment (22). Therefore, considering the importance of anatomy in medical education, this study was conducted with the aim of evaluating medical students knowledge about clinical importance and effective teaching methods of anatomy.

\section{Methods}

\subsection{Study Design}

This was a cross-sectional study carried out during October, 2015 to April, 2016. The study population included all preclinical and clinical medical students of Zahedan
University of Medical Sciences (ZAUMS), Zahedan, Iran. Through the convenience sampling method, 225 (120 preclinical and 105 clinical) medical students were selected in the study.

Despite the differences in naming various courses of medical curriculum in different countries, all the medical students passed preclinical and clinical courses. Medical curriculum in Iran included basic sciences, physiopathology, externship, and internship. Preclinical and clinical courses in Iranian medical curriculum are known as externship (24 months) and internship (18 months) courses, respectively.

Inclusion criteria were as follows, being a medical student at ZAUMS, passing all the anatomy courses, and willingness to participate in the study.

\subsection{Study Questionnaire}

Data were collected using a 3-part self-administered questionnaire, after proving its validity and reliability.

The first part included students' demographic characteristics, such as age, gender, course, grade point average (GPA) and ward. The second part consisted of 16 questions concerning the students' knowledge regarding the importance of anatomy and its usage in the clinic. The first 15 questions were closed-style with 2 options of "Yes" and "No". The answer no was scored as 1 and yes as 2 . The overall knowledge score was classified at 3 levels of knowledge; low (15 to 20 ), moderate (21 to 26 ), and high (27 to 30 ). The last question (question 16) was used to evaluate the medical students' purpose of studying anatomy. The third part of the questionnaire evaluated the students' viewpoint about the most effective way of learning anatomy, which could help improve their clinical skills and also draw their interest to anatomy.

\subsection{Validity and Reliability of the Questionnaire}

The validity of the questionnaire was proved using panel of experts method. For this purpose, the initial questionnaire was designed based on review of the literature $(10,13,23,24)$ and was then assessed and revised by 4 of the anatomy staff ( 3 anatomist), 4 clinical specialists (1 general surgeon, 1 internal medicine specialist, 1 orthopedist, and 1 emergency medicine specialist), and also 2 general practitioners. In the final questionnaire, CVI and CVR were calculated as 0.89 and 0.91 , respectively, and thus the validity was proved.

The reliability of the questionnaire was proved using the test-retest method; 15 students filled the questionnaire twice with a 2-week interval and correlation coefficient between the 2 times was 0.83 , indicating reliability. 


\subsection{Ethical Considerations}

This study was approved by the ethics committee of ZAUMS (IR.ZAUMS.REC.1396.18). Written informed consent was obtained from all participants students.

\subsection{Statistical Analysis}

Data were represented as descriptive statistics (mean, standard deviation, and frequency table) and analytical statistics ( $t$ test, ANOVA, Pearson correlation) by SPSS software version 16. The significance level was set at $\mathrm{P}<0.05$.

\section{Results}

A total of 225 students were included in the final analysis. The participants age ranged was between 18 and 27 with a mean of $22.12 \pm 3.24$. Most of the participants were female ( $n=117,52 \%)$, had a bachelor degree $(n=157,69.78 \%)$, and were in the preclinical $(n=120,53.34 \%)$ period and studying at an internal medicine ward $(n=60,26.70 \%)$. More demographic characteristics are presented in Table 1.

Table 1. Demographic Characteristics of the Medical Students ${ }^{\mathrm{a}}$

\begin{tabular}{|c|c|}
\hline Characteristics & Value \\
\hline Age, y, mean, (range) & $22.12 \pm 3.24(18-27)$ \\
\hline Grade point average, mean & $16.87 \pm 2.31$ \\
\hline \multicolumn{2}{|l|}{ Gender } \\
\hline Male & $108(48.00)$ \\
\hline Female & $117(52.00)$ \\
\hline \multicolumn{2}{|l|}{ Marital status } \\
\hline Bachelor & $157(69.78)$ \\
\hline Married & $68(30.22)$ \\
\hline \multicolumn{2}{|l|}{ Course } \\
\hline Preclinical & $120(53.34)$ \\
\hline Clinical & $105(46.66)$ \\
\hline \multicolumn{2}{|l|}{ Ward } \\
\hline Internal & $60(26.70)$ \\
\hline Surgery & $19(8.40)$ \\
\hline Orthopedics & $35(15.60)$ \\
\hline Emergency & $49(21.80)$ \\
\hline Neurology & $34(15.10)$ \\
\hline Cardiology & $28(12.40)$ \\
\hline
\end{tabular}

${ }^{\mathrm{a}}$ Values are expressed as No. (\%).

The study results showed no significant differences between students' level of knowledge and their age $(\mathrm{P}=0.23)$, gender $(P=0.07)$, and marital status $(P=0.09)$, yet the difference between their course $(\mathrm{P}=0.001)$ and ward $(\mathrm{P}=$ 0.001) and their level of knowledge was statistically significant.

Students mean overall knowledge score was $24.83 \pm$ 4.42, which is at a moderate level. Male students knowledge was $24.32 \pm 4.36$ and that of females was $25.29 \pm$ 4.45 , yet the difference between the 2 groups was not statistically significant. Preclinical students mean knowledge score was $23.05 \pm 4.14$ and that of clinical students was $26.83 \pm 3.90$, and there was a significant difference between these 2 groups so that clinical students had a higher level of knowledge than preclinical counterparts (Table 2).

The study findings showed that preclinical students studied anatomy mostly for passing the exam (52.50\%) whereas clinical students studied it mostly for improving their clinical skills (36.19\%) (Table 3).

Based on the study results, preclinical students stated that the most effective way of learning anatomy is giving lectures by the teacher whereas clinical students mentioned teaching the theoretical topics simultaneously with clinical tips as the most effective way (Table 4).

\section{Discussion}

Anatomy is a substantial course in medical education and health sciences, and all medical schools maintain anatomy as a main subject in their curricula (3). Medical students spend their first 2.5 years at the beginning of medical education on studying basic sciences, such as anatomy before being involved in their clinical clerkship (25). Anatomy has recently been undergoing some changes in medical schools of different universities, according to the demands of modern medical practice (26). However, didactic lectures and hands-on cadaveric dissection is still a common method of teaching anatomy in medical schools and theoretical lectures are completed by practical courses (27).

In the current study, the researchers asked medical students about an appropriate method for learning anatomy and examined their level of knowledge about the clinical significance of anatomy. The findings showed that there was a significant difference in the level of knowledge of anatomy between these 2 groups so that the senior students believed that their anatomy knowledge was critical in the application and practice of medicine and helped them to improve their clinical skills, and they were interested in theoretical lectures accompanied by clinical and applied anatomy. This result is in accordance with the study of Mazouchian et al., who concluded that medical students of Qazvin University were more interested in learning practical-theoretical skills when compared with theory alone (13). 
Table 2. Frequency of Knowledge Levels About the Clinical Importance of Anatomy From the Perspective of Medical Students

\begin{tabular}{lcccc}
\hline Courses & Levels of knowledge & Frequency, No. & Percentage & Mean \pm SD \\
\hline \multirow{2}{*}{ Preclinical } & Low & 55 & 45.80 & 28.30 \\
& Moderate & 22 & 35.80 \\
Clinical & High & 43 & 12.40 \\
& Low & 13 & 28.60 \\
\hline
\end{tabular}

Table 3. Medical Students' Viewpoint About Their Purpose of Studying Anatomy ${ }^{\mathrm{a}}$

\begin{tabular}{lcc|}
\hline $\begin{array}{l}\text { Purposes of Studying } \\
\text { Anatomy }\end{array}$ & Preclinical Students & Clinical Students \\
\hline $\begin{array}{l}\text { Success in exams } \\
\begin{array}{l}\text { Being interested in } \\
\text { anatomy }\end{array}\end{array}$ & $63(52.50)$ & $14(13.33)$ \\
\hline $\begin{array}{l}\text { Importance of anatomy in } \\
\text { medicine }\end{array}$ & $11(9.16)$ & $10(9.52)$ \\
$\begin{array}{l}\text { Clinical importance of } \\
\text { anatomy }\end{array}$ & $22(18.33)$ & $18(17.14)$ \\
\hline $\begin{array}{l}\text { Improving the necessary } \\
\text { clinical skills }\end{array}$ & $16(13.33)$ & $25(23.80)$ \\
\hline a Values are expressed as No. (\%). & & $38(36.19)$ \\
\hline
\end{tabular}

However, the preclinical students in the current study believed that giving theoretical lecture by teachers was an effective method for learning anatomy. This discrepancy may be due to differences in the level of education between these 2 groups of medical students so that the concern of clinical students was passing the medical basic science exam and they believed that theoretical lectures were enough for passing the exam. According to Ahmadinejad's study, the majority of medical students stated that theoretical lectures were an effective method for learning anatomy (28). Another study reported that improving lecturer's teaching skills and using proper coeducational tools result in better learning in anatomy lessons (29).

In another section of the present study, students' viewpoints about their purpose for studying anatomy were examined. The result showed that preclinical students studied anatomy for obtaining better marks in the medical basic science exam, yet clinical students, who passed the basic science exam, were interested in improving their skills.

According to the study of Gole et al., at the beginning of the anatomy course $100 \%$ of the students were interested in clinical practice yet at the 2 nd assessment when the syllabus of anatomy was completed, $32 \%$ of students changed their opinion and just wanted to pass the medical exam,
Table 4. The Most Effective Ways of Teaching Anatomy from the Medical Students' Viewpoint $^{\mathrm{a}}$

\begin{tabular}{|c|c|c|}
\hline Ways of Teaching Anatomy & Preclinical Students & Clinical Students \\
\hline $\begin{array}{l}\text { Giving lecture by the } \\
\text { teacher }\end{array}$ & $53(44.16)$ & $9(8.57)$ \\
\hline $\begin{array}{l}\text { Teaching useful clinical } \\
\text { topics simultaneously } \\
\text { with theoretical ones }\end{array}$ & $18(15)$ & $58(55.23)$ \\
\hline $\begin{array}{l}\text { Teaching only the useful } \\
\text { clinical topics }\end{array}$ & $7(5.83)$ & $12(11.42)$ \\
\hline $\begin{array}{l}\text { Using electronic devices } \\
\text { and educational slides }\end{array}$ & $9(7.50)$ & $6(5.71)$ \\
\hline $\begin{array}{l}\text { Using Molding, atlas, } \\
\text { corpse and microscope }\end{array}$ & $8(6.66)$ & $8(7.61)$ \\
\hline $\begin{array}{l}\text { Reviewing the theoretical } \\
\text { topics in practical classes }\end{array}$ & $6(5)$ & $4(3.80)$ \\
\hline $\begin{array}{l}\text { Providing booklets and a } \\
\text { summary by the teacher }\end{array}$ & $7(5.83)$ & $0(0)$ \\
\hline $\begin{array}{l}\text { Making a medical } \\
\text { dissection before the } \\
\text { theoretical class }\end{array}$ & $5(4.16)$ & $7(6.66)$ \\
\hline $\begin{array}{l}\text { Teacher's friendly behavior } \\
\text { and nice appearance }\end{array}$ & $3(2.5)$ & $1(0.95)$ \\
\hline $\begin{array}{l}\text { Regular exams during the } \\
\text { semester }\end{array}$ & $4(3.33)$ & $0(0)$ \\
\hline
\end{tabular}

which is in line with the current study (10).

Anatomy courses are important and a relatively large part of medical basic science exam in Iranian medical schools, and medical students have to learn a high volume of anatomy terms (many of them in Latin) and details with little understanding of their relevance in a limited time and there is considerable loss of anatomy knowledge and this may be the reason for the change in view point.

Anatomy plays an essential role in medical education and it is necessary to teach clinically relevant material (30). The majority of anatomists in Iran are traditional anatomists, who try to conserve the content of lessons and they didn't use new methods of teaching. According to the 
research of Hasanzadeh et al., 82\% of anatomists in Iran use lectures for teaching, and they believe that applied and clinical contents should be added to the theoretical lectures of anatomy (27).

One of the other hand, the questionnaire of the current study assessed students' attitudes toward the clinical significant of anatomy. The result showed that there was a significant difference between these 2 groups so that clinical students had a higher level of knowledge than preclinical students. This was in line with Kemeir's study, who reported that $60.4 \%$ of medical students in the preclinical phase at King Khalid University in Saudi Arabia claimed that the study of gross anatomy did not help them in clinical procedures (31).

The result of Mazouchian et al. showed that medical students of Tabriz University were not optimistic about the application of basic medical sciences in their practice (13). Ali et al. reported that a large number of medical students felt their anatomical knowledge was not adequate for their future jobs (32).

Results of several studies revealed that a great number of students believed that anatomy was taught with the traditional method and most of them were unable to remember what was taught during the preclinical phase $(31,33)$. On the other hand, the results of Nabil et al. demonstrated that $68 \%$ of the students strongly agreed about the importance of anatomy knowledge for their future role as physicians (25). This discrepancy in the current study between clinical and preclinical students' attitude about clinical significant of anatomy may have resulted from the insufficiency of anatomy knowledge in junior students.

In conclusion, considering that medical students need anatomy, modification of its teaching methods not only makes them more interested in anatomy yet can also help them improve their professional skills. According to the findings of the current study, learning anatomy plays an important role in improving clinical skills of medical students. It seems that changes in teaching methods and using novel methods may be effective for teaching and learning anatomy and improving students' attitudes towards the clinical importance of anatomy.

\section{Acknowledgments}

The authors acknowledge all students of ZAUMS, who participated in the present study. This study was extracted from a research grant (NO: 8223), which was approved at ZAUMS. The authors are highly appreciated by all medical students, who helped with this study.

\section{Footnotes}

Authors' Contribution: Enam Alhagh Charkhat Gorgich and Maryam Sarbishegi co-designed the study, Enam Alhagh Charkhat Gorgich and Maryam Sarbishegi were the project designers of the research and wrote the manuscript. Ayub Abedi and Sanam Barfroshan participated in collecting the data and analyzed the results. All authors read, modified, and approved the final version of the manuscript.

Financial Disclosure: None declared.

Funding/Support: The deputy research of ZAUMS financially supported this research.

\section{References}

1. Nagar S, Malukar O, Kubavat D, Prajapati V, Ganatra D, Rathwa A. Students'perception on anatomy teaching methodologies. Natl JMed Res. 2012;2(1):111-2.

2. Teunissen PW, Westerman M. Junior doctors caught in the clash: the transition from learning to working explored. Med Educ. 2011;45(10):968-70. doi: 10.1111/j.1365-2923.2011.04052.x. [PubMed: 21916936].

3. Pangaro LN. A shared professional framework for anatomy and clinical clerkships. Clin Anat. 2006;19(5):419-28. doi: 10.1002/ca.20257. [PubMed: 16317746].

4. Fasel JH, Morel P, Gailloud P. A survival strategy for anatomy. Lancet. 2005;365(9461):754. doi: 10.1016/S0140-6736(05)17981-1. [PubMed: 15733715].

5. Raftery AT. Anatomy teaching in the UK. Surge (Oxford). 2007;25(1):1-2. doi: 10.1016/j.mpsur.2006.11.002.

6. Craig S, Tait N, Boers D, McAndrew D. Review of anatomy education in Australian and New Zealand medical schools. ANZ J Surg. 2010;80(4):212-6. doi: 10.1111/j.1445-2197.2010.05241.x. [PubMed: 20575945].

7. Ramsden P. Learning to teach in higher education. ; 2003.

8. Siabani S, Moradi MR, Siabani H, Rezaei M, Siabani S, Amolaei K, et al. Students' view points on the educational problems in medical school of Kermanshah University of Medcial Sciences (2007) [In Persian]. J Kermanshah Univ Med Sci. 2009;13(2).

9. Hassanzadeh S, Amini A, Shagagie A, Hassanzadeh P. Medical students points of view on clinical skill lab function in 8 month period [In Persian]. Iran J Med Educ. 2002;2:27-8.

10. Gole RA, Meshram P, Hattangdi S. Changes in perception about anatomy subject after 1 st year of medical course. India JBasic Appl Med Res. 2015;4(4):453-7.

11. Ten Cate O. Medical education in The Netherlands. Med Teach. 2007;29(8):752-7. doi: 10.1080/01421590701724741. [PubMed: 18236272].

12. Alipour HM, Hasanzadeh GR, Haji Seied Javadi Z. Attitude of dentistry students at clinical sections of Qazvin Medical University towards the application of basic sciences courses [In Persian]. JQazvin Univ Med Sci. 2002;6(2):38-42.

13. Mazouchian H, Roshangar L, Ranjbarzadeh FS, Piri R, Shoar MK, Marzabadi LR. Medical students' view about the effects of practical courses on learning the general theoretical concepts of basic medical sciences. Res Dev. 2014;3(1):21-3.

14. Rezaee R, Keshtkar V. Basic sciences curriculum in medical education. JAdv Med Educ Prof. 2013;1(1):28-32. 
15. Mitchell BS, Xu Q, Jin L, Patten D, Gouldsborough I. A cross-cultural comparison of anatomy learning: learning styles and strategies. Anat Sci Educ. 2009;2(2):49-60. doi: 10.1002/ase.73. [PubMed: 19347948].

16. Moxham BJ, Plaisant O. Perception of medical students towards the clinical relevance of anatomy. Clin Anat. 2007;20(5):560-4. doi: 10.1002/ca.20453. [PubMed:17149736].

17. Reidenberg JS, Laitman JT. The new face of gross anatomy. Anat Rec. 2002;269(2):81-8. doi:10.1002/ar.10076. [PubMed: 12001214].

18. Mehr-Mohammadi M. Curriculum: Views, attitudes and perspectives. Tehran: Ministry of Culture and Islamic Guidance Publication; 2008.

19. Bergman EM, de Bruin AB, Herrler A, Verheijen IW, Scherpbier AJ, van der Vleuten $C P$. Students' perceptions of anatomy across the undergraduate problem-based learning medical curriculum: a phenomenographical study. BMC Med Educ. 2013;13:152. doi: 10.1186/14726920-13-152. [PubMed: 24252155].

20. Dahle LO, Brynhildsen J, Behrbohm Fallsberg M, Rundquist I, Hammar M. Pros and cons of vertical integration between clinical medicine and basic science within a problem-based undergraduate medical curriculum: examples and experiences from Linkoping, Sweden. Med Teach. 2002;24(3):280-5. doi: 10.1080/01421590220134097. [PubMed:12098414].

21. Dolmans DH, De Grave W, Wolfhagen IH, van der Vleuten CP. Problem-based learning: future challenges for educational practice and research. Med Educ. 2005;39(7):732-41. doi: 10.1111/j.13652929.2005.02205.x. [PubMed: 15960794].

22. Gorgich EAC, Arbabisarjou A, Abedi A, Barfrushan S. Knowledge of medical sciences collegians about protection against crimean-congo hemorrhagic fever (CCHF). Int J Hum Cult Stud. 2016;3(1):1642-53.

23. Turney BW. Anatomy in a modern medical curriculum. Ann R Coll Surg Engl. 2007;89(2):104-7. doi: 10.1308/003588407X168244. [PubMed: 17346399].

24. Plaisant O, Stephens S, Apaydin N, Courtois R, Lignier B, Loukas M, et al. Medical students' attitudes towards science and gross anatomy, and the relationship to personality. J Anat. 2014;224(3):261-9. doi: 10.1111/joa.12043. [PubMed: 23594196]

25. Nabil N, AlMously N, AlWathnani S, Abduldaiem A, AlIssa H. Medical students perception on anatomy knowledge relevance and retention during clerkship. J Contemp Med Educ. 2014;2(3):147-51. doi: 10.5455/jcme.20140928035119.

26. McLachlan JC, Bligh J, Bradley P, Searle J. Teaching anatomy without cadavers. Med Educ. 2004;38(4):418-24. doi: 10.1046/j.13652923.2004.01795.x. [PubMed: 15025643].

27. Hassanzadeh G, Hassanpoor N, Jalali A, Hassanzadeh N, Jafari M Panahi N. Teaching anatomy: Viewpoints of iranian anatomists. Thrita J Med Sci. 2012;1(2):62-6. doi: 10.5812/thrita.6434.

28. Ahmadinejad Z, Ziaee V, Morravedgi A. A survey on students satisfaction of clinical education and its related factor In Persian]. Iran J Med Educ. 2002;2:15-6.

29. Fahimi Manzari S, Sam S, Pourghasem M. Effective methods on teaching and learning of anatomy course [In Persian]. Q Educ Strat Med Sci. 2013;6(2):95-9.

30. Dangerfield P, Bradley P, Gibbs T. Learning gross anatomy in a clinical skills course. Clin Anat. 2000;13(6):444-7. doi: 10.1002/10982353(2000)13:6<444::AID-CA9>3.0.CO;2-W. [PubMed: 11111897].

31. Kemeir MA. Attitudes and views of medical students toward anatomy learnt in the preclinical phase at King Khalid University.J Family CommunityMed. 2012;19(3):190-3. doi:10.4103/2230-8229.102320. [PubMed: 23230386].

32. Ali A, Khan ZN, Konczalik W, Coughlin P, El Sayed S. The perception of anatomy teaching among UK medical students. Bul R Coll Surg Engl. 2015;97(9):397-400. doi: 10.1308/rcsbull.2015.397.

33. Alam A. How do medical students in their clinical years perceive basic sciences courses at King Saud University? Ann Saudi Med. 2011;31(1):5861. doi: 10.4103/0256-4947.75780. [PubMed: 21245601]. 